\title{
Prevalence of undernutrition among Santal children of Birbhum District, West Bengal, India
}

\author{
Jyoti Ratan Ghosh ${ }^{1}$, Avipsa Sarkar ${ }^{2}$ \\ Sri Lanka Journal of Child Health, 2013; 42(3): 147-150
}

\begin{abstract}
Objectives: To determine the prevalence of undernutrition in terms of stunting, underweight and thinness among Santal children of Birbhum district, West Bengal, India.

Method: Heights and weights of 203 children (100 boys) aged 2-16 years were measured. Children were considered to have stunting, underweight and thinness if their height-for-age, weight-for-age and body mass index-for-age Z-scores were below -2.0 SD of the WHO references.
\end{abstract}

Results: Overall prevalence of stunting, underweight and thinness in the study population was $47.8 \%$, $31.1 \%$ and $29.6 \%$, respectively. There were no significant sex differences $(p>0.05)$ in the prevalence of underweight and thinness but the prevalence of stunting was significantly $(p<0.05)$ higher in girls. Overall prevalence of moderate stunting, underweight and thinness was $23.7 \%, 26.1 \%$ and $18.3 \%$, respectively. Odds of stunting was 1.86 times higher in girls than boys $(\mathrm{OR}=1.859$; 95\% CI, 1.064 $3.246 ; p<0.05)$ whereas the odds of underweight $(\mathrm{OR}=0.995 ; 95 \% \quad \mathrm{CI}, 0.458-2.163 ; p>0.05)$ and thinness $(\mathrm{OR}=1.054 ; 95 \% \mathrm{CI}, 0.577-1.927 ; p>0.05)$ were similar in boys and girls.

Conclusion: The present study in Santal children of Birbhum district revealed poor nutritional status with a higher incidence of stunting.

(Key words: Tribe; thinness; stunting; Santal; underweight; undernutrition)

\section{Introduction}

More than one third of the world's wasted and stunted children live in India. Undernutrition endangers children's survival, health, growth and development, slows national progress towards the

\footnotetext{
${ }^{1}$ Assistant Professor, ${ }^{2} M S c$ Student, Department of
} Anthropology, Visva-Bharati University, India

(Received on 31 March 2013: Accepted after revision on 4 May 2013) developmental goals and thus diminishes the strength and capacity of nation ${ }^{1,2}$. Undernutrition is substantially higher in rural than in urban areas and children from scheduled tribes have the poorest nutritional status ${ }^{3,4}$. Santal, the third largest tribe in India, represented $54.3 \%$ of the total tribal population in West Bengal ${ }^{5}$. Traditionally, they were forest dwellers, but now they have started cultivation and are also engaged in other activities like daily labour.

There are several ways of measuring nutritional status. Anthropometry is especially important during childhood and adolescence because growth may be sensitive to nutritional shortage and surplus and provide indicators of nutritional status and health risk $^{6}$. Three most commonly used anthropometric indices in assessing nutritional status are derived by comparing height and weight measurements with reference curves, i.e. height-for-age, weight-for-age and body mass index-for-age.

There is little information on the nutritional status of children and adolescents in different tribal populations in India ${ }^{7-9}$. Moreover, to the best of our knowledge, there was no information on the nutritional status, as assessed by World Health Organization (WHO) recommended ${ }^{10} \mathrm{Z}$-scores for height-for-age, weight-for-age and body mass indexfor-age among Santal children. In view of the above, the present study reports the prevalence of undernutrition in terms of stunting, underweight and thinness among Santal children in Birbhum district of West Bengal, India.

\section{Method}

The present community based cross-sectional study was conducted in two villages of Birbhum district, about $150 \mathrm{~km}$ from Kolkata city. A total of 203 (boys $=100$, girls $=103$ ) children aged 2-16 years were assessed. The minimum estimated sample size was 75 , calculated using standard formula $\left(n=\mathrm{Z}^{2} \mathrm{pq} / \mathrm{d}^{2}\right)^{7}$. The calculation $\left[\left(1.96^{2} \times 0.261 \times 0.739\right) /\left(0.10^{2}\right)\right]$ was based on $26.1 \%$ prevalence (p) of stunting in a community based study ${ }^{7}$, with precision (d) of $\pm 10 \%$. Where, $\mathrm{q}=\mathrm{p}-1$ and $\mathrm{z}=1.96$. Informed consent was obtained from the parents of each child before commencement of the study. 
Information on ethnicity, age and gender was collected on a pre-tested questionnaire. Children's ages were recorded as reported by mother and verified further with other senior members of the family. Anthropometric measurements such as height (HT) and weight (WT) were made following the standard technique ${ }^{11}$. HT was measured to the nearest $0.1 \mathrm{~cm}$ using a moveable anthropometer. WT was measured to the nearest $0.5 \mathrm{~kg}$ using a weighing machine. Body mass index (BMI, $\mathrm{kg} / \mathrm{m}^{2}$ ) was derived subsequently. Age and sex specific mean height, weight and BMI of the Santal children were compared with the World Health Organization (WHO) standards ${ }^{10}$. Children were considered as having stunting, underweight and thinness if their height-for-age, weight-for-age and BMI-for-age Zscores were below $-2.0 \mathrm{SD}$ of the WHO reference ${ }^{10}$. However, for the assessment of weight-for-age Zscores, we considered only children aged 10 years or below, because of the lack of WHO reference values for weight-for-age above 10 years of age. We followed the $\mathrm{WHO}^{6}$ classification for assessing severe (Z-scores <-3.0) and moderate (Z-scores -3.0 to $<-2.0)$ malnutrition by rate prevalence ranges of these three indicators among children. Chi-square test was performed to test for differences in prevalence. Odds ratio (OR) was also calculated. Statistical analyses were performed using the SPSS package. A $\mathrm{p}$ value of $<0.05$ was considered as significant.

\section{Results}

The age and sex specific means of HT, WT and BMI were analyzed. It was observed that the mean HT, WT and BMI increased with advancement of age. Comparisons of mean HT, WT and BMI -for-age of the Santal children with the WHO median reference values are presented in figures 1 and 2 . The prevalence of undernutrition in terms of stunting, underweight and thinness are presented in table 1.

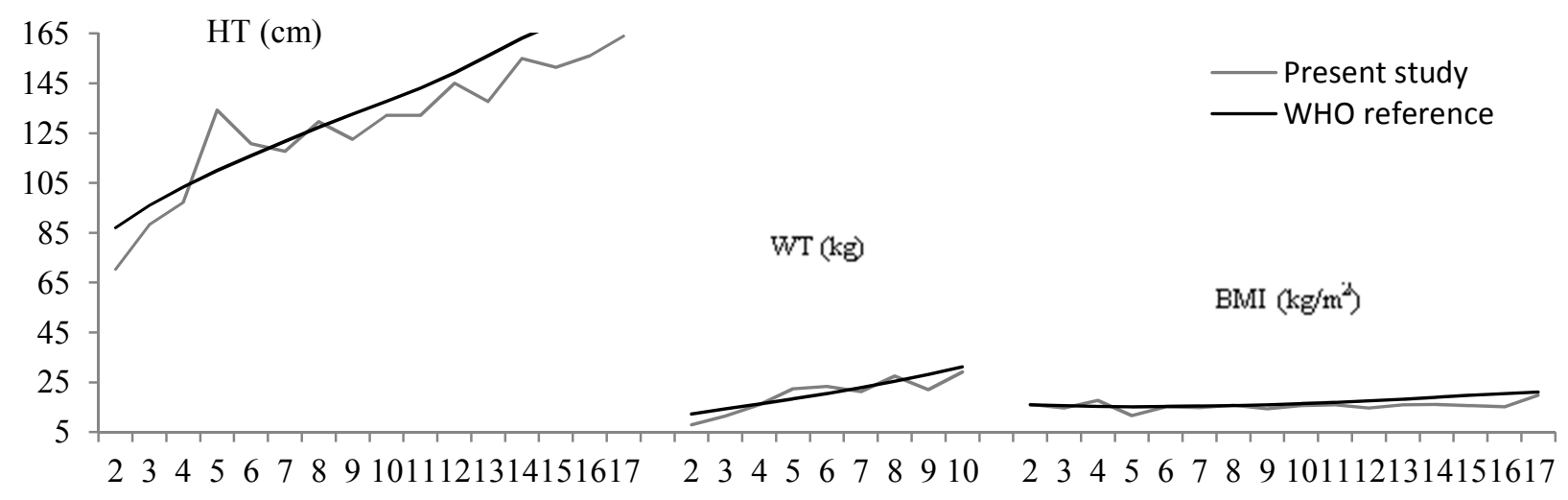

Figure 1:Mean height (HT), weight (WT) and body mass index (BMI) -for-age of the Santal boys compared with the World Health Organization (WHO) reference median values

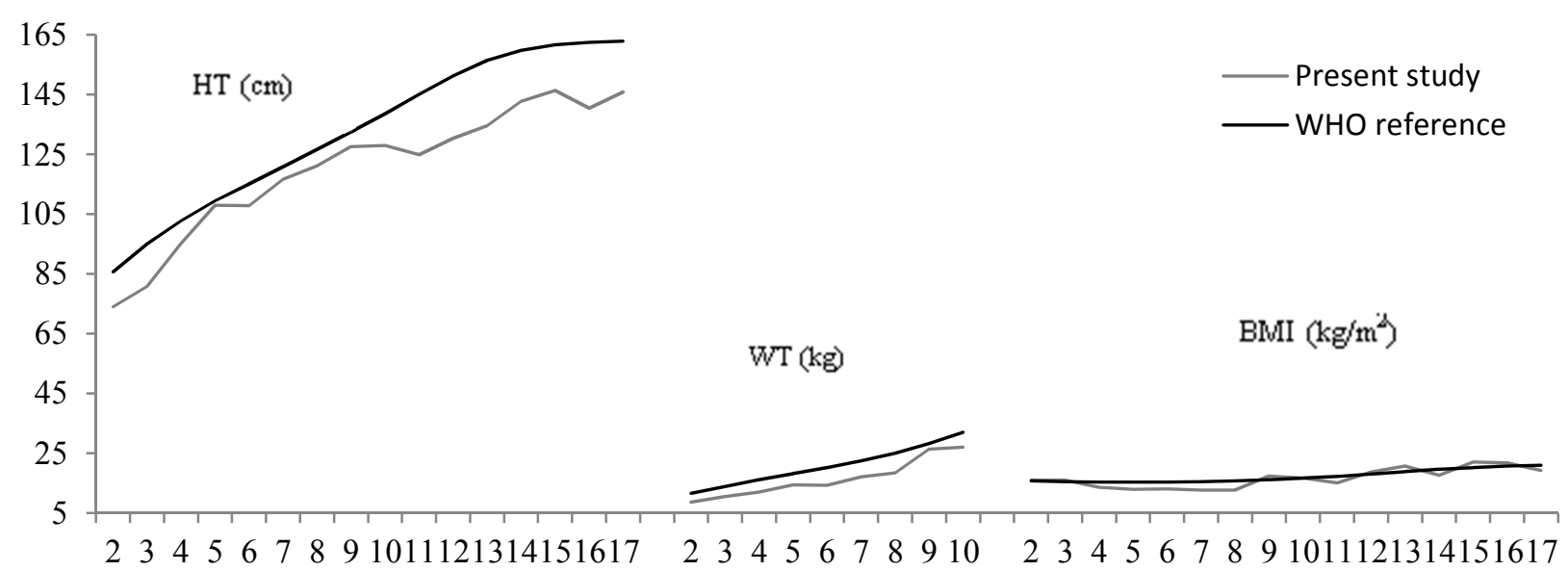

Figure 2:Mean height (HT), weight (WT) and body mass index (BMI) -for-age of the Santal girls compared with the World Health Organization (WHO) reference median values 
Table 1: Prevalence of stunting, underweight and thinness

\begin{tabular}{|l|c|c|c|}
\hline Nutritional indicators & $\begin{array}{c}\text { Total undernutrition } \\
(\mathbf{\%})\end{array}$ & $\begin{array}{c}\text { Moderate undernutrition } \\
\mathbf{( \% )}\end{array}$ & $\begin{array}{c}\text { Severe } \\
\text { undernutrition(\%) }\end{array}$ \\
\hline Stunting & & & \\
Boys (100) & $40(40)$ & $21(21)$ & $19(19)$ \\
Girls (103) & $57(55.3)$ & $27(26.2)$ & $30(29.1)$ \\
All (203) & $97(47.8)$ & $48(23.7)$ & $49(24.1)$ \\
\hline Underweight* & $19(31.1)$ & $16(26.2)$ & $3(4.9)$ \\
Boys (61) & $18(31.0)$ & $15(25.8)$ & $3(5.2)$ \\
Girls (58) & $37(31.1)$ & $31(26.1)$ & $6(5.0)$ \\
All (119) & & & \\
\hline Thinness & $29(29)$ & $17(17)$ & $12(12)$ \\
Boys (100) & $31(30.1)$ & $20(19.4)$ & $11(10.7)$ \\
Girls (103) & $60(29.6)$ & $37(18.3)$ & $23(11.3)$ \\
All (203) & & & \\
\hline
\end{tabular}

*in children $\leq 10$ years

Overall prevalence of stunting, underweight and thinness in the study population was $47.8 \%, 31.1 \%$ and $29.6 \%$, respectively. There were no significant sex differences $(p>0.05)$ in the prevalence of underweight (boys, $31.1 \%$ vs. girls, $31 \%$, in children $\leq 10$ years) and thinness (boys, $29 \%$ vs. girls, $30.1 \%$ ) in the study population. However, prevalence of stunting was significantly $(p<0.05)$ higher in girls $(55.3 \%)$, compared to boys $(40 \%)$. The cardinal feature was the higher prevalence of severe undernutrition in terms of stunting $(29.1 \%$ vs. $19 \%)$ and underweight $(5.2 \%$ vs. $4.9 \%)$ in girls compared to boys. On the other hand, prevalence of thinness was higher in boys $(12 \%)$ compared to girls $(10.7 \%)$. Overall prevalence of moderate stunting, underweight and thinness was $23.7 \%$ (boys $21 \%$, girls $26.2 \%$ ), $26.1 \%$ (boys $26.2 \%$, girls $25.8 \%$ ) and $18.3 \%$ (boys, $17 \%$, girls $19.4 \%$ ), respectively.

When the children were divided into $\leq 10$ years and $>10$ years, it was observed that in boys, prevalence of stunting ( $23 \%$ vs. $17 \%$ ) was higher in early childhood and prevalence of thinness $(13.0 \%$ vs. $16.0 \%)$ was higher in late childhood. Contrary to that, in girls, the prevalence of stunting $(24.27 \%$ vs. $31.08 \%)$ was higher in late childhood and the prevalence of thinness $(24.27 \%$ vs. $5.83 \%)$ was higher in early childhood compared to late childhood. However, the prevalence of underweight (in children $\leq 10$ years) was $(31.1 \%$ vs. $31.0 \%)$ similar in both boys and girls. Moreover, the odds of stunting was 1.86 times higher in girls than boys $(\mathrm{OR}=1.859 ; 95 \% \mathrm{CI}, 1.064-3.246$; $p<0.05$ ). Whereas, the odds of underweight $(\mathrm{OR}=0.995 ; \quad 95 \% \quad \mathrm{CI}, 0.458-2.163 ; p>0.05)$ and thinness $(\mathrm{OR}=1.054 ; 95 \% \mathrm{CI}, 0.577-1.927 ; p>0.05)$ was similar in boys and girls.

\section{Discussion}

It appears from the present study that undernutrition was widely prevalent among the Santal children. Examination of children's nutritional status according to the WHO's Z-score classification ${ }^{10}$ indicated that the overall prevalence of stunting, underweight and thinness in the study population was $47.8 \%, 31.1 \%$ and $29.6 \%$, respectively. However, prevalence of severe undernutrition i.e. stunting, underweight and thinness was $24.1 \%, 5 \%$ and $11.3 \%$ respectively. Comparison of prevalence of undernutrition in the present study with other tribal populations revealed a higher prevalence of stunting in the present study ${ }^{7,8}$. In brief, comparison with the Lodha children ${ }^{7}$ revealed extremely higher prevalence of stunting among the Santal children of the present study $(47.8 \%$ vs. $26.1 \%)$, but the prevalence of underweight was slightly lower $(31.1 \%$ vs. $33.9 \%)$ than the Lodha children. Comparison with the Garasia children of Rajasthan ${ }^{8}$ also revealed higher prevalence of stunting ( $47.8 \%$ vs. $45.45 \%)$, though, the prevalence of thinness was lower in the Santal children $(29.6 \%$ vs. $64.5 \%)$. On the other hand, when we compare with other studies ${ }^{5,7}$, prevalence of severe stunting was higher in the present study $(24.1 \%$ vs. $9.7 \%$ and $4.98 \%)$.

In general, the incidence of underweight and thinness in the study population was similar in boys and girls. However, the prevalence of stunting was significantly $(p<0.05)$ higher in girls $(55.3 \%)$, compared to boys $(40 \%)$. This concurs with the previous study ${ }^{5}$, but contradicts the studies in other tribal populations, where the prevalence of stunting ${ }^{3,12}$, underweight ${ }^{3,12}$ and thinness ${ }^{8}$ was higher in boys than in girls. However, with regard to severe undernutrition, the prevalence of severe stunting and severe underweight was higher in girls $(29.1 \%$ and $5.2 \%)$ compared to 
boys (19\% and $4.9 \%)$. Conversely the prevalence of severe thinness was higher in boys $(12 \%)$ compared to girls $(10.7 \%)$.

Interestingly, when the children were divided into $\leq 10$ years and $>10$ years, it was observed that in boys, prevalence of stunting (23\% vs. $17 \%)$ was higher in early childhood and prevalence of thinness $(13.0 \%$ vs. $16.0 \%)$ was higher in late childhood. Contrary to that, in girls, the prevalence of stunting $(24.3 \%$ vs. $31.1 \%)$ was higher in late childhood and prevalence of thinness $(24.3 \%$ vs. $5.8 \%)$ was higher in early childhood compared to late childhood. However, prevalence of underweight (in children $\leq 10$ years) was similar in both boys and girls $(31.1 \%$ vs. $31.0 \%$ ). A recent study among Santal preschool children $^{13}$ also observed higher incidence of thinness in girls of early childhood. Moreover, the odds of stunting was 1.86 times higher in girls than boys $(\mathrm{OR}=1.859 ; 95 \% \mathrm{CI}, 1.064-3.246 ; p<0.05)$, whereas, the odds of underweight $(\mathrm{OR}=0.995 ; 95 \% \mathrm{CI}, 0.458$ $2.163 ; p>0.05)$ and thinness $(\mathrm{OR}=1.054 ; 95 \% \mathrm{CI}$, $0.577-1.927 ; p>0.05$ ) was similar in boys and girls.

Thus, the present study in Santal children of Birbhum district revealed poor nutritional status with a higher incidence of stunting. However, one of the limitations of the present study is the small sample size. Further studies are needed among a larger sample for effective planning of nutritional intervention programmes.

\section{References}

1. United Nations International Children's Emergency Fund [homepage on the Internet]. New Delhi: United Nations International Children's Emergency Fund; c2011; [cited 2011 Feb 2]. Available from: http://www.unicef.org/india/nutrition.html

2. Bose K, Chakraborty F, Mitra K, Bisai S. Nutritional status of adult Santal men in Keonjhar district, Orissa, India. Food and Nutrition Bulletin 2006; 27(4): 353-6.

3. Mitra M, Sahu PK, Chakrabarty S, Bharati S, Bharati P. Nutritional and health status of Gond and Kawar tribal pre-school children of Chhattisgarh, India. Journal of Human Ecology. 2007; 21(4): 293-9.

4. Kanjilal B, Mazumdar PG, Mukherjee M, Rahman MH. Nutritional status of children in India: household socio-economic condition as the contextual determinant. International Journal for Equity in Health. 2010;9(1): 19 http://dx.doi.org/10.1186/1475-9276-9-19

5. Chowdhury SD, Chakraborty T, Ghosh T. Prevalence of undernutrition in Santal children of Puruliya district, West Bengal. Indian Pediatrics 2008; 45(1): 43-6.

6. World Health Organization. Physical status: the use and interpretation of anthropometry. Technical Report Series No. 854. Geneva: World Health Organization. 1995.

7. Bisai S, Bose K, Ghosh A. Prevalence of undernutrition of Lodha children aged 1-14 years of Paschim Medinipur district, West Bengal, India. Iran Journal of Pediatrics 2008; 18(4): 323-9.

8. Mandot S, Mandot D, Sonesh JK. Nutritional status of tribal (Garasia) school children of Sirohi district, Rajasthan. Indian Pediatrics. 2009; 46 (5); 437-8.

9. Das S, Bose K. Prevalence of thinness using new international cut-off points among Santal tribal children and adolescents of Purulia District, West Bengal, India. Sri Lanka Journal of Child Health. 2011; 40(3): 105-10. http://dx.doi.org/10.4038/sljch.v40i3.3507

10. World Health Organization [homepage on the Internet]. Geneva: World Health Organization; c2011; [cited 2011 Feb 2]. Available from: http://www.who.int/childgrowth/standards/en/

11. Lohman TG, Roche AF, Martorell R. Anthropometric standardization reference manual. Illinois: Human Kinetic. 1988.

12. Bisai S, Mallick C. Prevalence of undernutrition among Kora-Mudi children aged 2-13 years in Paschim Medinipur District, West Bengal, India. World Journal of Pediatrics. 2011; 7(1):31-6. http://dx.doi.org/10.1007/s12519-010-0239-3

13. Das S, Bose K. Prevalence of thinness among Santal preschool children using new body mass index cut-off points. Journal of Anthropology. 2011. Available from: http://www.hindawi.com/journals/janth/2011/60 $\underline{2782 /}$ 